\title{
Folic acid supplementation during pregnancy and associations with offspring size at birth and adiposity: a cohort study
}

\author{
Clive J. Petry ${ }^{1 *}\left(\mathbb{0}\right.$, Ken K. Ong ${ }^{1,2,3}$, leuan A. Hughes ${ }^{1}$ and David B. Dunger ${ }^{1,3}$
}

\begin{abstract}
Objective: Previously we observed that maternal multiple micronutrient supplementation in pregnancy was associated with increased offspring size at birth and adiposity, as well as with maternal gestational diabetes risk, in the Cambridge Baby Growth Study. In this study we therefore investigated whether folic acid supplementation specifically is associated with similar changes, to test the hypothesis that folic acid supplementation mediates such changes.

Results: The majority of mothers who reported supplementing with folic acid in pregnancy ( $n=776$ in total, 526 of which took multiple micronutrient preparations) did so either from pre- $(n=139)$ or post-conception $(n=637)$ largely for all or just the first half of pregnancy. A minority of mothers $(n=198)$ reported not supplementing with folic acid. Folic acid supplementation in pregnancy was not associated with birth weight $\left[\beta^{\prime}=-0.003, p=0.9\right]$, height $\left[\beta^{\prime}=-0.013, p=0.6\right]$, head circumference $\left[\beta^{\prime}=0.003, p=0.09\right]$ or adiposity (ponderal index $\left[\beta^{\prime}=0.020, p=0.5\right]$, skinfolds thicknesses $\left[\beta^{\prime}=-0.029\right.$ to $\left.+0.008, p=0.4-0.9\right]$ ). Neither was it associated with the development of maternal gestational diabetes (risk ratio $1.2[0.6-2.2], p=0.6$ ). These results suggest that folic acid supplementation in pregnancy did not mediate the previously observed increases in offspring size at birth and adiposity, or the raised gestational diabetes risk, in response to supplementation with multiple micronutrients.
\end{abstract}

Keywords: Pregnancy, Growth, Development, Gestational diabetes

\section{Introduction}

Multiple micronutrient supplementation in pregnancy leads to a reduced risk of the baby being born with a low birth weight, and possibly one for being born small for its gestational age (SGA) [1]. Consistent with this, we recently studied the effects of multiple micronutrient supplementation in pregnancy in the prospective, longitudinal Cambridge Baby Growth Study (CBGS) and found that it was associated with increased size

\footnotetext{
*Correspondence: cjp1002@cam.ac.uk

${ }^{1}$ Department of Paediatrics, University of Cambridge, Cambridge

Biomedical Campus, Hills Road, Cambridge CB2 0QQ, UK

Full list of author information is available at the end of the article
}

(including weight and head circumference) and adiposity (skinfold thicknesses in the flank, subscapular and triceps regions) at birth [2]. In the mothers it was associated with increased risk of developing gestational diabetes (GDM), and most of the associations with increased offspring size at birth and adiposity were somewhat attenuated by adjusting the statistical models for GDM. This suggests a role for the processes involved in increasing offspring size at birth in GDM pregnancies [3] in possibly mediating the increased size at birth and adiposity in offspring whose mothers supplemented with multiple micronutrients in pregnancy.

In iron replete women in the U.K. the only micronutrients that are specifically recommended to supplement 
dietary intake with during pregnancy (and whilst attempting to get pregnant) are folic acid (at a dose of $400 \mu \mathrm{g}$ per day) and, in certain months of the year, vitamin D [4]. Folic acid supplementation in pregnancy, often taken as part of multiple micronutrient preparations, has been associated with both increased $[5,6]$ and decreased [7] risk of GDM in the mother, and decreased risk of SGA in the offspring [8] in previous studies. We therefore investigated the effects of folic acid supplementation in pregnancy on offspring size at birth and adiposity, as well as adverse pregnancy outcomes on the mother in the CBGS, testing the hypothesis that our previous findings with multiple micronutrient supplementation [2] were mediated specifically by folic acid supplementation.

\section{Main text \\ Methods \\ Cambridge baby growth study}

The initial phase of the CBGS involved recruiting 2229 participants from 2001-9 and has been described in detail elsewhere [9]. At recruitment from the booking clinic at the Rosie Maternity Hospital, Cambridge, U.K., each participant was given an extensive questionnaire to fill in as pregnancy progressed [10]. Around week 28 of pregnancy 1074 of the women underwent standard $75 \mathrm{~g}$ oral glucose tolerance tests after fasting overnight, and GDM status was defined from these, as previously described [11]. Blood pressure measurements across pregnancy (plus diagnoses related to high blood pressure) were collected retrospectively from hospital notes in 720 of the participants to increase the amount of useful available information; gestational hypertension status was defined from these as previously described [12].

From all the women recruited to the CBGS during this time the following were excluded from the present analysis: those that had already withdrawn from the study before the birth of their baby, twin pregnancies (because of the impact of multifetal pregnancies on offspring size at birth), and those that did not fill in (specifically the questions about maternal supplement intake during pregnancy) and return their pregnancy questionnaire.

Offspring birth weights were recorded from hospital notes. Other newborn measurements (length, head circumference, skinfold thickness at flank, quadriceps, subscapular and triceps regions) were made by trained paediatric nurses as soon as possible after birth [at a median (inter-quartile range) age of $2(1-16)$ days], as described [13]. Low birth weight, SGA, and pre-term status were also defined as described [2]. The body mass index (BMI) was calculated as the body weight (pre-pregnancy for the mother) divided by the height or length squared, and the ponderal index calculated as the body weight divided by the length cubed. Pregnancy weight gain was calculated as the maternal pre-pregnancy weight subtracted from the pregnancy weight (from the final week of pregnancy), both of which were collected from the pregnancy questionnaire.

This analysis, using results from the CBGS cohort, was run in an unmatched exposed $v$. non-exposed format as per that of our multiple micronutrient supplementation study [2]. The exposed group contained women who either supplemented with multiple micronutrients in pregnancy that included folic acid or supplemented with folic acid specifically (largely either in isolation or in combination with iron later in pregnancy). Folic acid supplementation dosage (both daily and total) in this group was calculated using the questionnaire (checking the folic acid content of the reported supplement used on the internet), plus the length of reported time that the folic acid was supplemented. The non-exposed group contained women who either did not take dietary supplements in pregnancy, or who took supplements that did not include folic acid (e.g. iron in isolation, vitamin C, or vitamin D with or without added calcium).

\section{Statistical analysis}

Risk ratios of adverse pregnancy outcomes by folic acid supplementation were analysed by log-binomial regression. Other categorical variables were analysed using $\chi^{2}$ or Fisher's exact tests (as appropriate). Continuous variables were analysed using linear regression, adjusted for confounders where appropriate. Where the dependent variable residuals were skewed, the models were analysed with prior transformation of the data so that they were normally distributed. Missing data were treated by case or listwise deletion. $\mathrm{P}<0.05$ was considered statistically significant throughout. Stata (version 13.1; Stata Corp., from Timberlake Consultants Ltd., Richmond, Surrey, U.K.) was used to perform the statistical analyses.

\section{Results and interpretation}

This analysis included 974 pregnancies: 776 with mothers that supplemented with folic acid and 198 that did not. Of those that supplemented with folic acid, most $(n=526)$ did so via the form of multiple micronutrient supplementation (Table 1). In terms of when they started supplementing, there was a bimodal distribution (Fig. 1a). This may have reflected one group of women who presumably were planning a pregnancy and therefore started supplementing prior to its onset, as recommended [4], and another group of women who started to supplement as soon as they knew that they were pregnant or as soon as the concept of supplementing came to their attention. The total length of time that women supplemented was also bimodal (Fig. 1b): one group of women seemed to supplement with folic acid throughout pregnancy, while 
Table 1 A comparison of the characteristics of CBGS participants by folic acid supplementation in pregnancy

\begin{tabular}{|c|c|c|c|}
\hline Maternal Characteristic & No folic acid supplementation & Folic acid supplementation & p-value \\
\hline $\begin{array}{l}\text { Supplemented with multiple micronutrients (all of } \\
\text { which contained folic acid) }\end{array}$ & $\begin{array}{l}0 \text { yes } \\
198 \text { no }\end{array}$ & $\begin{array}{l}526 \text { yes } \\
250 \text { no }\end{array}$ & $<0.001$ \\
\hline Age (years) & $33.1(32.5-33.7)(n=179)$ & $33.6(33.3-33.9)(n=710)$ & 0.2 \\
\hline Height (m) & $1.65(1.64-1.66)(n=180)$ & $1.66(1.66-1.67)(n=729)$ & 0.2 \\
\hline Pre-pregnancy weight (kg) & $67.0(65.0-69.0)(n=177)$ & $66.1(65.1-67.1)(n=708)$ & 0.4 \\
\hline Weight gain in pregnancy (kg) & $7.5(6.3-8.6)(n=121)$ & $8.7(8.2-9.3)(n=523)$ & 0.1 \\
\hline Pre-pregnancy BMI (kg/m²) & $24.5(23.9-25.2)(n=172)$ & $24.0(23.6-24.3)(n=693)$ & 0.1 \\
\hline Smoked during pregnancy & $\begin{array}{l}11 \text { yes } \\
184 \text { no }\end{array}$ & $\begin{array}{l}20 \text { yes } \\
742 \text { no }\end{array}$ & 0.03 \\
\hline Parity (n of pregnancies) & $2.0(1.9-2.1)(n=195)$ & $1.7(1.6-1.8)(n=761)$ & $<0.001$ \\
\hline Anaemia & $\begin{array}{l}3 \text { yes } \\
183 \text { no }\end{array}$ & $\begin{array}{l}19 \text { yes } \\
717 \text { no }\end{array}$ & 0.6 \\
\hline GDM & $\begin{array}{l}11 \text { yes } \\
112 \text { no }\end{array}$ & $\begin{array}{l}57 \text { yes } \\
489 \text { no }\end{array}$ & 0.6 \\
\hline Pre-eclampsia & $\begin{array}{l}3 \text { yes } \\
195 \text { no }\end{array}$ & $\begin{array}{l}12 \text { yes } \\
764 \text { no }\end{array}$ & 1.0 \\
\hline Gestational hypertension & $\begin{array}{l}7 \text { yes } \\
78 \text { no }\end{array}$ & $\begin{array}{l}21 \text { yes } \\
366 \text { no }\end{array}$ & 0.3 \\
\hline Premature birth ( $<37$ weeks gestation) & $\begin{array}{l}3 \text { yes } \\
192 \text { no }\end{array}$ & $\begin{array}{l}14 \text { yes } \\
748 \text { no }\end{array}$ & 1.0 \\
\hline Length of pregnancy (weeks) & $39.9(39.7-40.1)(n=195)$ & $39.9(39.8-40.0)(n=762)$ & 1.0 \\
\hline Offspring low birth weight & $\begin{array}{l}5 \text { yes } \\
190 \text { no }\end{array}$ & $\begin{array}{l}21 \text { yes } \\
739 \text { no }\end{array}$ & 0.9 \\
\hline Offspring SGA at birth (n no/yes) & $\begin{array}{l}0 \text { yes } \\
195 \text { no }\end{array}$ & $\begin{array}{l}5 \text { yes } \\
755 \text { no }\end{array}$ & 0.6 \\
\hline
\end{tabular}

Data are mean (95\% confidence interval) or number of participants

another group tended to supplement for up to half of pregnancy (as recommended [4]). The modal dose of folic acid supplemented with was $400 \mu \mathrm{g} /$ day (again as recommended [4]) (Fig. 1c).

Most of the maternal clinical characteristics did not differ between those women that supplemented and those that did not (Table 1). However, the average parity was lower in those that supplemented with folic acid; also, proportionally fewer smoked in pregnancy in those that supplemented (in a cohort where smoking in pregnancy was rare [9]). Folic acid supplementation in pregnancy was not associated with any of the adverse outcomes of pregnancy that were tested [mean risk ratio $(95 \%$ confidence interval)]: GDM $1.2(0.6-2.2)$, gestational hypertension 0.7 (0.3-1.5), pre-eclampsia 1.0 (0.3-3.6), anaemia 1.6 (0.5-5.4), pre-term birth 1.6 (0.5-5.4), low birth weight $1.1(0.4-2.8)$.

The lack of association with GDM risk is inconsistent with other studies investigating links between folic acid supplementation and risk of GDM but results from these studies are themselves inconsistent with both higher [5, 6] and lower [7] risk being reported. One study found that the risk for GDM was both dose- and supplementationlength dependent [14]. Results from the current study are inconsistent with this, however, as the dose of folic acid supplemented with (either expressed as the daily dose or the total dose) or duration of supplementation were also not associated with GDM [all risk ratios (95\% confidence intervals): $1.0(1.0-1.0)]$. This inconsistency may be due to the lack of participants in the present analysis who supplemented with high dose folic acid [14]. Results from previous studies seeking associations between folic acid supplementation in pregnancy and blood pressurerelated outcomes have been equivocal. Consistent with the results that we observed, one meta-analysis shown no associations between folic acid supplementation in pregnancy and gestational hypertension or pre-eclampsia [15]. Another meta-analysis, however, found such supplementation to be associated with a reduced risk of preeclampsia [16]. Previous results are also equivocal for associations between folic acid supplementation in pregnancy and risk of preterm birth, with two meta-analyses showing no association $[17,18]$, like we observed, and others showing a reduced risk of preterm birth $[19,20]$. One meta-analysis also found folic acid supplementation in pregnancy to be associated with a reduced risk of low birth weight, although only at high doses [21]. Given that in our analysis the bulk of the women who supplemented 

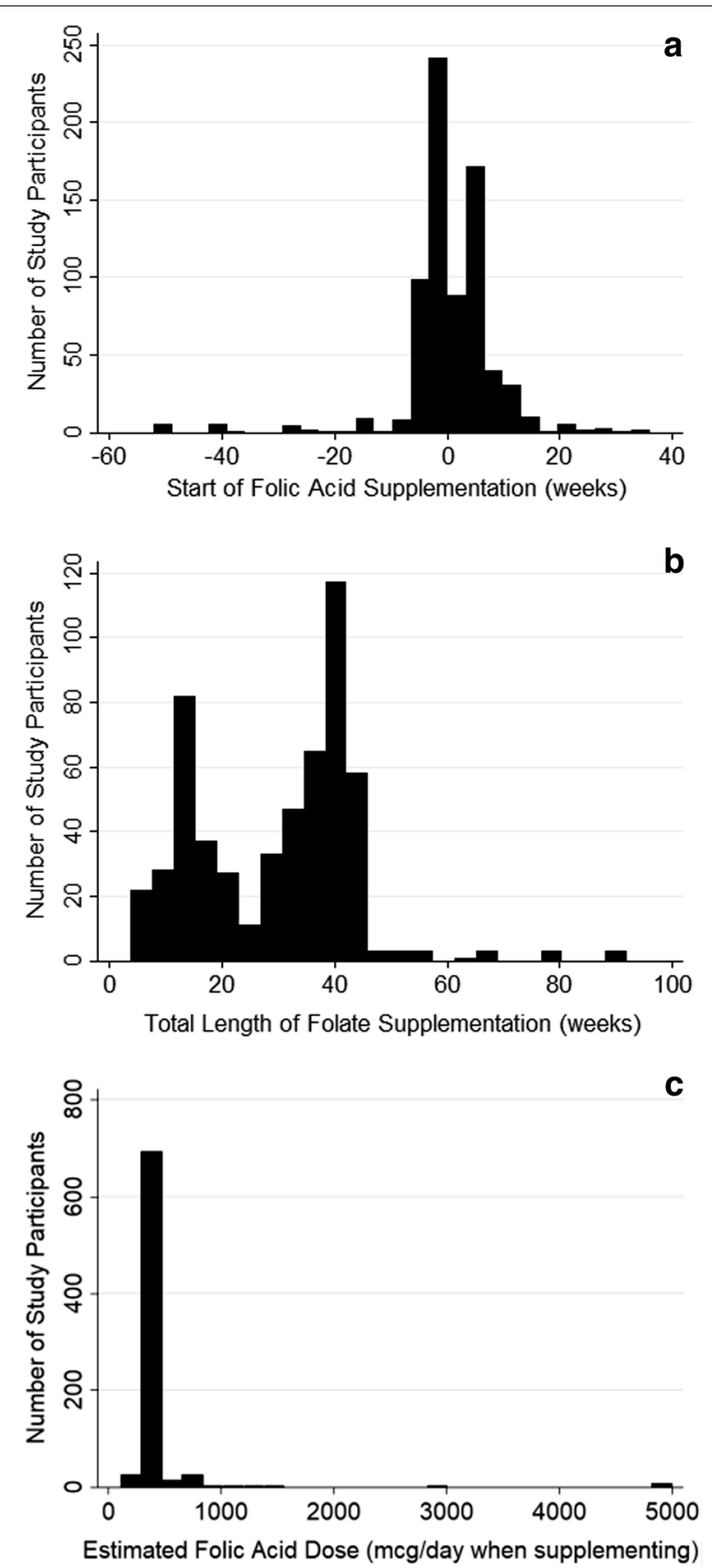

Fig. 1 Participant numbers by the $\mathbf{a}$ start, $\mathbf{b}$ length and $\mathbf{c}$ dose of folic acid supplementation

with folic acid did so in the form of multiple micronutrient supplements, where the dose of folic acid was generally that recommended for pregnant women rather than higher doses, our results are therefore not inconsistent with this.

Folic acid supplementation in pregnancy was not associated with any index of offspring size at birth or adiposity (Table 2). Once again data on this subject published in the literature have been conflicting. Two meta-analyses found no association with birth weight $[17,21]$ but an increase in birth weight was found in two other metaanalyses [18, 22], one of which was in a dose-dependent manner [18]. No previous studies in humans have investigated offspring adiposity at birth where mothers supplemented their diets with folic acid in pregnancy. In the present analysis, given that maternal folic acid supplementation failed to show associations with any of the other markers of size at birth, it is not surprising that there were no significant associations with either BMI (or ponderal index) or any of the skinfold thicknesses.

In conclusion, in the present analysis we could not find any associations between folic acid supplementation in pregnancy and either adverse outcomes of pregnancy or markers of offspring size at birth or adiposity. This is not surprising given that the literature contains highly conflicting studies in this area. Although peri-conceptional folic acid supplementation remains the most suitable preventative measure to lower risk of neural tube defects in the offspring [23], in this analysis we could find no evidence to suggest that the increases in offspring size at birth and adiposity in women that supplemented with multiple micronutrients in pregnancy might have resulted specifically from folic acid supplementation.

\section{Limitations}

- Folic acid supplementation in pregnancy was selfreported, which could have led to inaccurate categorisation.

- Dietary folic acid intake was not recorded, so the folic acid supplementation doses may not have borne much resemblance to the total daily folic acid intakes.

- As the exposed group in this analysis contained both women who supplemented their diets with folic acid in isolation and those whose folic acid was included in multiple micronutrient preparations, the negative results could have been affected by confounding effects of other micronutrients. If folic acid had mediated the previously observed significant associations with multiple micronutrient supplementation [2], however, it would have been expected that the rationale used in this analysis would have strengthened these associations not attenuated them.

- Missing data were manifest for most of the variables and were dealt with by case or listwise deletion. In particular, missing data related to the supplementation with folic acid during pregnancy (e.g. missing due to the lack of filling in the pregnancy questionnaire in the section related to supplementation, or not returning it) could have introduced biases to the study. 
Table 2 Associations between folic acid supplementation status in pregnancy and indices of offspring size at birth

\begin{tabular}{|c|c|c|c|c|}
\hline Measure & $\begin{array}{l}\text { No maternal } \\
\text { Folic acid supplementation }\end{array}$ & $\begin{array}{l}\text { Maternal } \\
\text { Folic acid supplementation }\end{array}$ & Standardised $\beta(\times 100)$ & $\mathrm{p}$-value \\
\hline Weight (kg) & $3.5(3.4-3.6)(n=172)$ & $3.5(3.5-3.5)(n=689)$ & $-0.3(-5.9$ to 5.2$)$ & 0.9 \\
\hline Length $(\mathrm{cm})^{\mathrm{a}}$ & $51.5(51.2-51.8)(n=165)$ & $51.4(51.3-51.6)(n=674)$ & $-1.3(-6.3$ to 3.6$)$ & 0.6 \\
\hline Head Circumference $(\mathrm{cm})^{\mathrm{a}}$ & $35.3(35.1-35.5)(n=166)$ & $35.3(35.2-35.4)(n=674)$ & $0.6(-4.3$ to 5.5$)$ & 0.8 \\
\hline $\mathrm{BMI}\left(\mathrm{kg} / \mathrm{m}^{2}\right)^{\mathrm{a}}$ & $13.1(12.9-13.3)(n=165)$ & $13.2(13.1-13.3)(n=672)$ & $1.0(-4.4$ to 6.3$)$ & 0.7 \\
\hline Ponderal Index $\left(\mathrm{kg} / \mathrm{m}^{3}\right)^{\mathrm{a}}$ & $25.5(25.1-25.9)(n=165)$ & $25.7(25.5-25.8)(n=672)$ & $2.0(-3.2$ to 7.1$)$ & 0.5 \\
\hline Flank skinfold thickness $(\mathrm{mm})^{\mathrm{a}}$ & $6.2(6.0-6.5)(n=166)$ & $6.1(6.0-6.2)(n=673)$ & $-2.9(-8.8$ to 3.5$)$ & 0.4 \\
\hline Quadriceps skinfold thickness $(\mathrm{mm})^{\mathrm{a}}$ & $8.0(7.6-8.3)(n=166)$ & $8.0(7.8-8.1)(n=673)$ & $-0.4(-5.8$ to 5.0$)$ & 0.9 \\
\hline Subscapular skinfold thickness $(\mathrm{mm})^{\mathrm{a}}$ & $5.4(5.2-5.6)(n=166)$ & $5.4(5.3-5.5)(n=673)$ & $-2.0(-8.1$ to 4.1$)$ & 0.5 \\
\hline Triceps skinfold thickness $(\mathrm{mm})^{\mathrm{a}}$ & $5.5(5.3-5.7)(n=166)$ & $5.5(5.4-5.6)(n=673)$ & $0.8(-5.4$ to 7.1$)$ & 0.8 \\
\hline
\end{tabular}

Data and standardised $\beta$ s are presented as mean (95\% confidence interval)

All models adjusted for gestational age at birth, parity, smoking during pregnancy, offspring sex and maternal pre-pregnancy BMI

${ }^{\text {a }}$ Models additionally adjusted for age at assessment

- The lack of significant statistical associations observed could theoretically be caused by insufficient statistical power if the true effect sizes were very small (i.e. a type II statistical error). However, they still clearly do not explain the significant associations detectable with multiple micronutrient supplementation in pregnancy [2].

\section{Abbreviations \\ BMI: Body mass index; CBGS: Cambridge Baby Growth Study; GDM: Gesta- tional diabetes; SGA: Small for gestational age.}

\section{Acknowledgements}

The authors are extremely grateful to Dr. Carlo Acerini, who was the Principal Investigator of the Cambridge Baby Growth Study prior to his death in May 2019. We acknowledge the excellent technical assistance for this project that was provided by Dianne Wingate, Karen Whitehead and Angie Watts (all University of Cambridge, Department of Paediatrics). The authors would like to thank all the families that took part in the Cambridge Baby Growth Study, and acknowledge the crucial role played by the research nurses especially Suzanne Smith, Ann-Marie Wardell, and Karen Forbes (all University of Cambridge, Department of Paediatrics), staff at the Addenbrooke's Wellcome Trust Clinical Research Facility, and midwives at the Rosie Maternity Hospital.

\section{Authors' contributions}

$\mathrm{KKO}, \mathrm{IAH}$ and DBD are principal investigators of the CBGS and raised grant funding to run the study. CJP and DBD designed this investigation and wrote initial drafts of the manuscript. CJP extracted the folic acid data from the pregnancy questionnaires and performed the statistical analysis. All authors interpreted the data analysis, substantially commented on the manuscript. All authors read and approved the final manuscript.

\section{Funding}

This study received funding from the European Union Framework 5 (QLK4-1999-01422); the Medical Research Council (7500001180, G1001995, U106179472); the World Cancer Research Fund International (2004/03); Newlife Foundation for Disabled Children (07/20) and the Mothercare Charitable Foundation (RG54608). We also acknowledge support from National Institute for Health Research Cambridge Biomedical Research Centre. KKO receives support from the Medical Research Council (Unit Programme number: MC_UU_12015/2 and MC_UU_00006/2).

\section{Availability of data and materials}

The dataset analysed during the current study is available in the University of Cambridge Apollo repository, https://doi.org/10.17863/CAM.59641.

\section{Declarations}

\section{Ethics approval and consent to participate}

The CBGS was granted ethical approval by the Cambridge Local Research Ethics Committee, Addenbrooke's Hospital, Cambridge, U.K. (00/325). All procedures followed were in accordance with the institutional guidelines. Written informed consent was obtained from all women (for themselves and on behalf of their baby).

\section{Consent for publication}

Not applicable.

\section{Competing interests}

The authors declare that they have no competing interests.

\section{Author details}

${ }^{1}$ Department of Paediatrics, University of Cambridge, Cambridge Biomedical Campus, Hills Road, Cambridge CB2 0QQ, UK. ${ }^{2}$ MRC Department of Epidemiology, University of Cambridge, Cambridge, UK. ${ }^{3}$ Institute of Metabolic Science, University of Cambridge, Cambridge, UK.

Received: 17 November 2020 Accepted: 20 April 2021

Published online: 30 April 2021

\section{References}

1. Keats EC, Haider BA, Tam E, Bhutta ZA. Multiple-micronutrient supplementation for women during pregnancy. Cochrane Database Syst Rev. 2019:3:CD004905.

2. Petry CJ, Ong KK, Hughes IA, Dunger DB. Multiple micronutrient supplementation during pregnancy and increased birth weight and skinfold thicknesses in the offspring: the Cambridge Baby Growth Study. Nutrients. 2020;12:3466.

3. Prentice PM, Olga L, Petry CJ, Simmons D, Murphy HR, Hughes IA, Acerini $\mathrm{CL}$, Ong KK, Dunger DB. Reduced size at birth and persisting reductions in adiposity in recent, compared with earlier, cohorts of infants born to mothers with gestational diabetes mellitus. Diabetologia. 2019:62:1977-87. 
4. Vitamins, supplements and nutrition in pregnancy: your pregnancy and baby guide. https://www.nhs.uk/conditions/pregnancy-and-baby/vitam ins-minerals-supplements-pregnant/. Accessed 06 Nov 2020.

5. Cheng G, Sha T, Gao X, He Q, Wu X, Tian Q, et al. The associations between the duration of folic acid supplementation, gestational diabetes mellitus, and adverse birth outcomes based on a birth cohort. Int J Environ Res Public Health. 2019;16:E4511.

6. Huang L, Yu X, Li L, Chen Y, Yang Y, Yang Y, et al. Duration of periconceptional folic acid supplementation and risk of gestational diabetes mellitus. Asia Pac J Clin Nutr. 2019;28:321-9.

7. Li M, Li S, Chavarro JE, Gaskins AJ, Ley SH, Hinkle SN, et al. Prepregnancy habitual intakes of total, supplemental, and food folate and risk of gestational diabetes mellitus: a prospective cohort study. Diabetes Care. 2019;42:1034-41.

8. Hodgetts VA, Morris RK, Francis A, Gardosi J, Ismail KM. Effectiveness of folic acid supplementation in pregnancy on reducing the risk of smallfor-gestational age neonates: a population study, systematic review and meta-analysis. BJOG. 2015;122:478-90.

9. Prentice P, Acerini CL, Eleftheriou A, Hughes IA, Ong KK, Dunger DB. Cohort profile: the Cambridge Baby Growth Study (CBGS). Int J Epidemiol. 2016;45:35.a-35.g.

10. Petry CJ, Ong KK, Hughes IA, Acerini CL, Dunger DB. Temporal trends in maternal food intake frequencies and associations with gestational diabetes: the Cambridge Baby Growth Study. Nutrients. 2019;11:E2822.

11. Petry CJ, Mooslehner K, Prentice P, Hayes MG, Nodzenski M, Scholtens $\mathrm{DM}$, et al. Associations between a fetal imprinted gene allele score and late pregnancy maternal glucose concentrations. Diabetes Metab. 2017;43:323-31.

12. Petry CJ, Sanz Marcos N, Pimentel G, Hayes MG, Nodzenski M, Scholtens DM, et al. Associations between fetal imprinted genes and maternal blood pressure in pregnancy. Hypertension. 2016;68:1459-66.

13. De Lucia RE, Modi N, Uthaya S, Hughes IA, Dunger DB, Acerini C, Stolk RP, Ong KK. Ultrasound estimates of visceral and subcutaneous-abdominal adipose tissues in infancy. J Obes. 2013;2013:951954.

14. Li Q, Zhang Y, Huang L, Zhong C, Chen R, Zhou X, et al. High-dose folic acid supplement use from prepregnancy through midpregnancy is associated with increased risk of gestational diabetes mellitus: a prospective cohort study. Diabetes Care. 2019;42:e113-5.
15. Hua X, Zhang J, Guo Y, Shen M, Gaudet L, Janoudi G, Walker M, Wen SW. Effect of folic acid supplementation during pregnancy on gestational hypertension/preeclampsia: a systematic review and meta-analysis. Hypertens Pregnancy. 2016;35:447-60.

16. Bulloch $R E$, Lovell $A L$, Jordan $V M B$, McCowan $L M E$, Thompson JMD, Wall CR. Maternal folic acid supplementation for the prevention of preeclampsia: a systematic review and meta-analysis. Paediatr Perinat Epidemiol. 2018;32:346-57.

17. Saccone G, Berghella V. Folic acid supplementation in pregnancy to prevent preterm birth: a systematic review and meta-analysis of randomized controlled trials. Eur J Obstet Gynecol Reprod Biol. 2016;199:76-81.

18. Fekete K, Berti C, Trovato M, Lohner S, Dullemeijer C, Souverein OW, Cetin I, Decsi T. Effect of folate intake on health outcomes in pregnancy: a systematic review and meta-analysis on birth weight, placental weight and length of gestation. Nutr J. 2012;11:75.

19. Li B, Zhang $X$, Peng $X$, Zhang S, Wang $X$, Zhu C. Folic acid and risk of preterm birth: a meta-analysis. Front Neurosci. 2019;13:1284.

20. Zhang Q, Wang Y, Xin X, Zhang Y, Liu D, Peng Z, He Y, Xu J, Ma X. Effect of folic acid supplementation on preterm delivery and small for gestational age births: a systematic review and meta-analysis. Reprod Toxicol. 2017;67:35-41.

21. Charles DH, Ness AR, Campbell D, Smith GD, Whitley E, Hall MH. Folic acid supplements in pregnancy and birth outcome: re-analysis of a large randomised controlled trial and update of Cochrane review. Paediatr Perinat Epidemiol. 2005;19:112-24.

22. Lassi ZS, Salam RA, Haider BA, Bhutta ZA. Folic acid supplementation during pregnancy for maternal health and pregnancy outcomes. Cochrane Database Syst Rev. 2013;2013:CD006896.

23. Viswanathan M, Treiman KA, Kish-Doto J, Middleton JC, Coker-Schwimmer EJ, Nicholson WK. Folic acid supplementation for the prevention of neural tube defects: an updated evidence report and systematic review for the US Preventive Services Task Force. JAMA. 2017;317:190-203.

\section{Publisher's Note}

Springer Nature remains neutral with regard to jurisdictional claims in published maps and institutional affiliations.
Ready to submit your research? Choose BMC and benefit from:

- fast, convenient online submission

- thorough peer review by experienced researchers in your field

- rapid publication on acceptance

- support for research data, including large and complex data types

- gold Open Access which fosters wider collaboration and increased citations

- maximum visibility for your research: over 100M website views per year

At BMC, research is always in progress.

Learn more biomedcentral.com/submissions 